Volumen 24, No 1, Páginas 49-61

IDESIA (Chile) Enero - Abril 2006

\title{
LA MATERIA ORGÁNICA, IMPORTANCIA Y EXPERIENCIAS DE SU USO EN LA AGRICULTURA
}

\author{
ORGANIC MATTER, IMPORTANCE, EXPERIENCES \\ AND IT ROLE IN AGRICULTURE
}

\author{
Alberto Julca-Otiniano ${ }^{1}$; Liliana Meneses-Florián ${ }^{1}$; Raúl Blas-Sevillano ${ }^{1}$; Segundo Bello-Amez ${ }^{2}$
}

\begin{abstract}
RESUMEN
Una primera mirada al suelo muestra una homogeneidad relativa, sin embargo, existe una comunidad subterránea con cadenas tróficas complejas y diversas, mantenidas por los productos de las raíces en la rizósfera. Las raíces son una fuente de complejos recursos que varían química y morfológicamente, en interacción con la microflora y fauna del suelo encargados de la descomposición y mineralización de la materia orgánica. El estudio de los microorganismos en el suelo es un reto, pues son variadas las técnicas y metodologías que se requieren para ello. Este documento presenta una revisión de las fracción orgánica del suelo, su rol y experiencias de la incorporación de materia orgánica al suelo.
\end{abstract}

Palabras clave: Materia orgánica, cadenas Aróficas, comunidad subterránea, microflora y fauna del suelo.

\begin{abstract}
Soils appear to be relatively homogeneous at first glance; however an underground community exist with complex, long and diverse trophic webs, supported by the rhizosphere (root and root by-products). Roots are a source of complex and varying chemical and morphological resources for the microflora and fauna which are in charge of the decomposition and mineralization of organic matter. There exists a clear interaction between both elements in the underground system.

The study of soil microorganisms is a challenge as many experimental methodologies and techniques are required. This document presents a review of the soil organic fraction, and its role and experiences in the incorporation of organic matter to the soil.

Key words: Organic matter, tropic webs, soil microflora and fauna.
\end{abstract}

\section{INTRODUCCIÓN}

El uso de materia orgánica se ha convertido en la base para el desarrollo de agricultura orgánica. Sin embargo, es un error considerar que agricultura orgánica es simplemente "no usar productos sintéticos". La agricultura orgánica debe considerar dos aspectos esenciales: (a) la diversidad estructural y de procesos, y (b) el manejo ecológico del suelo y nutrición (Brenes, 2003). Por ello, teniendo en cuenta la importancia del suelo en este proceso, este documento presenta una revisión sobre el rol de la fracción orgánica y las experiencias de la aplicación de materia orgánica en los suelos agrícolas.
El hombre ha aplicado toda clase de materias orgánicas a los suelos cultivados. Durante 150 años los fisiólogos mantuvieron la teoría húmica, que consideraba que las plantas se nutrían directamente del humus del suelo y la presencia de este material marcaba su fertilidad (Navarro et al., 1995). Sin embargo, la revolución agrícola promovida en el siglo XIX por Justus von Liebig (1843) demostró que las plantas precisan de agua y sustancias inorgánicas para su nutrición y puso en duda que el humus fuera el principio nutritivo de las plantas. Además, fomentó el desarrollo de los fertilizantes inorgánicos, que son de 20 a 100 veces más concentrados en elementos básicos como N, P, K, que los abonos orgánicos (Arens, 1983), lo que supuso

\footnotetext{
1 Universidad Nacional Agraria La Molina, Depto. Fitotecnia. Aptdo. 456. La Molina. Lima, E-mail: ajo@lamolina.edu.pe

2 Agrícola Italia. Jr. Apurímac 248. San Ramón. Chanchamayo. Junín.
}

Fecha de Recepción: 26 Febrero de 2006

Fecha de Aceptación: 24 Marzo de 2006 
un indudable efecto positivo en la agricultura, aumentando los rendimientos y provocando el abandono de muchas técnicas antiguas de cultivo, una de las cuales fue el uso de residuos orgánicos como abono de los cultivos (Navarro et al., 1995).

Según Mustin (1987), la materia orgánica representa del 95 al $99 \%$ del total del peso seco de los seres vivos, pero su presencia en los suelos suele ser escasa y son contadas las excepciones en las que supera el 2\% (Navarro et al., 1995). Para Gros y Domínguez (1992), el nivel deseable de materia orgánica en los suelos arcillosos medios es del $2 \%$, perdiendo descender a $1,65 \%$ en suelos pesados y llegar a un 2,5\% en los arenosos.

La materia orgánica del suelo contiene cerca del $5 \%$ de $\mathrm{N}$ total, pero también contiene otros elementos esenciales para las plantas, tales como fósforo, magnesio, calcio, azufre y micronutrientes (Anónimo, 1988; Graetz, 1997). Durante la evolución de la materia orgánica en el suelo se distinguen dos fases: la humidificación y la mineralización (Gros y Domínguez, 1992). La humidificación es una fase bastante rápida, durante la cual los microorganismos del suelo actúan sobre la materia orgánica desde el momento en que se la entierra.

Primero se forma el humus joven, de evolución rápida, que a su vez da paso al humus estable. Ambos productos forman la llamada materia orgánica total del suelo. Al humus joven también se le llama "lábil" o "libre", porque todavía no está fijado o ligado a las partículas del suelo, sino simplemente mezclado con ellas, tiene una relación $\mathrm{C} / \mathrm{N}$ superior a 15 , es sede de una intensa actividad microbiana y se le puede considerar como un elemento fundamental de la fertilidad del suelo. En promedio se estima que es el 20-25\% del humus total y tiene una acción inmediata más importante, desde el punto de vista de la mejora de la estructura y de la actividad microbiana del suelo. El humus estable o "estabilizado" es la materia orgánica ligada al suelo, es decir, sólidamente fijada a los agregados de color oscuro. Su composición es muy compleja (húmina, ácidos húmicos y fúlvicos) y tiene una relación $\mathrm{C} / \mathrm{N}$ constante entre 9 y 10 , y representa en promedio el $75-80 \%$ del humus total. La fase de mineralización es muy lenta, y en ella el humus estable recibe la acción de otros microorganismos que lo destruyen progresivamente $(1 \mathrm{al}$ $2 \%$ al año), liberando así los minerales que luego absorberán las plantas. Esta fase presenta dos eta- pas: la amonificación (paso del $\mathrm{N}$ orgánico a amonio) y la nitrificación (paso del amonio a nitrato).

\section{LA MATERIA ORGÁNICA DEL SUELO}

Los autores denominan indistintamente materia orgánica (Navarro et al., 1995) o humus (Gros y Domínguez, 1992) a la parte orgánica que cumple un papel esencial en el suelo. No existe una definición de humus con la que todos los especialistas estén de acuerdo; pero, en general, el término humus designa a las "sustancias orgánicas variadas, de color pardo y negruzco, que resultan de la descomposición de materias orgánicas de origen exclusivamente vegetal". Contiene aproximadamente un 5\% de nitrógeno, por lo que su valor en el suelo se puede calcular multiplicando por 20 su contenido en nitrógeno total (Gros y Domínguez, 1992).

El humus tiene efecto sobre las propiedades físicas del suelo, formando agregados y dando estabilidad estructural, uniéndose a las arcillas y formando el complejo de cambio, favoreciendo la penetración del agua y su retención, disminuyendo la erosión y favoreciendo el intercambio gaseoso. Cuando se refiere al efecto sobre las propiedades químicas del suelo, los autores mencionan que aumenta la capacidad de cambio del suelo, la reserva de nutrientes para la vida vegetal y la capacidad tampón del suelo favorece la acción de los abonos minerales y facilita su absorción a través de la membrana celular de las raicillas. Y en cuanto a su efecto sobre las propiedades biológicas, favorece los procesos de mineralización, el desarrollo de la cubierta vegetal, sirve de alimento a una multitud de microorganismos y estimula el crecimiento de la planta en un sistema ecológico equilibrado. Estos efectos de la materia orgánica también han sido sugeridos por otros autores (Anónimo, 1988; Graetz, 1997).

Para Jhonstom (1991), la cantidad de humus en el suelo depende de muchos factores, tales como la incorporación de nuevos restos orgánicos al suelo y su velocidad de oxidación química y biológica, la velocidad de descomposición de la materia orgánica existente ya en el suelo, la textura del suelo, la aireación, humedad y los factores climáticos. Las prácticas de manejo del cultivo también pueden tener un efecto sobre este parámetro, ya que, por ejemplo, el empleo de abonos minerales acele- 
ra la descomposición de la materia orgánica en el suelo. Esto es una manifestación del crecimiento de la actividad biológica, que se traduce en la práctica en una mejora de la fertilidad y, por tanto, de los rendimientos (Gros y Domínguez, 1992).

La materia orgánica en el suelo también facilita los mecanismos de absorción de sustancias peligrosas como los plaguicidas. Por ejemplo, se sabe que la capacidad del suelo para adsorber compuestos químicos como clorofenoles o cloroanilinas aumenta con el contenido en materia orgánica (Vangestel, 1996). La aplicación de enmiendas orgánicas también aumenta la degradación de fumigantes como el 1,3-D (Gan, et al., 1998a), bromuro de metilo y el isotiocianato metilo (Gan et al., 1998b) y disminuye la volatilización de estos tres pesticidas, cuando la enmienda se aplica en los primeros $5 \mathrm{~cm}$ del suelo (Gan et al., 1998a; Gan et al., 1998b). Los pesticidas con materiales catiónicos son firmemente adsorbidos por los coloides del suelo; en cambio, con los pesticidas ácidos hay muy poca adsorción, por lo tanto, se concentran en la solución suelo y en las fases gaseosas (Cremlyn, 1991).

\section{LOS MICROORGANISMOS DEL SUELO}

Según Wild (1992) un suelo naturalmente fértil es aquél en el que los organismos edáficos van liberando nutrientes inorgánicos, a partir de las reservas orgánicas, con velocidad suficiente para mantener un crecimiento rápido de las plantas. La actividad biológica de los suelos es la resultante de las funciones fisiológicas de los organismos y proporciona a las plantas superiores un medio ambiente adecuado para su desarrollo. Pero la exigencia de los microorganismos edáficos en energía, elementos nutritivos, agua, temperaturas adecuadas y ausencia de condiciones nocivas es similar a la de las plantas cultivadas.

Los suelos contienen una amplia variedad de formas biológicas, con tamaños muy diferentes, como los virus, bacterias, hongos, algas, colémbolos, ácaros, lombrices, nemátodos, hormigas y, por supuesto, las raíces vivas de las plantas superiores (Fassbender, 1982; Wild, 1992). La importancia relativa de cada uno de ellos depende de las propiedades del suelo (Thompson y Troeh, 1988).

Las bacterias son organismos procariotas unicelulares; la mayor parte de ellas presenta forma esférica cocos o de bastón bacilos y son importantes debido a que algunas realizan funciones específicas como la oxidación del amoniaco a nitratos, mientras que otras intervienen en el proceso general de descomposición de materiales orgánicos (Thompson y Troeh, 1988).

Los actinomicetos son organismos procariotas filamentosos; sus hifas son cenocíticas, tienen el diámetro de las bacterias y de la arcilla gruesa y están con frecuencia ramificadas y entrelazadas, por lo cual son difíciles de contar (Thompson y Troeh, 1988). Nutricionalmente, se trata de un grupo muy adaptable, sus miembros son heterótrofos sin excepción y pueden utilizar una amplia gama de compuestos carbonados y nitrogenados, como polisacáridos, lípidos, hidrocarburos saturados, fenoles, proteínas y quitina. Son organismos típicamente aeróbicos, por lo que no suelen encontrarse en suelos encharcados, son más frecuentes en los suelos calientes que en los fríos y resultan muy poco tolerantes a la acidez (Wild, 1992).

Los hongos, según Wild (1992), pueden representar el $70 \%$ de la población microbiana y constituyen el segundo de los dos grandes grupos de microorganismos del suelo. Todos son eucariotas heterótrofos y se incluyen entre las especies que necesitan nitrógeno, ya sea en forma de sales minerales o de compuestos orgánicos nitrogenados, pues están desprovistos de capacidad fijadora. Las especies edáficas presentan gran diversidad en cuanto a exigencias en sustratos carbonados, variando desde los que pueden utilizar hidratos de carbono, alcoholes y ácidos orgánicos sencillos hasta los que son capaces de descomponer compuestos polimerizados, como la celulosa y la lignina. Este es el caso de los que son parásitos obligados de los vegetales superiores o de los que han desarrollado una simbiosis obligada con determinadas plantas, como las micorrizas. Los saprófitos comunes en el suelo pueden ser eficaces transformadores de sustratos edáficos en tejidos microbianos. Algunos de ellos pueden asimilar entre el $30 \mathrm{y}$ $50 \%$ del carbono presente en la materia orgánica que descomponen, lo que representa una tasa de conversión muy superior a la de las bacterias, que es del 5 al 20\%. Esto significa que el crecimiento muy rápido de los hongos puede originar una elevada demanda del nitrógeno disponible en el suelo, aunque ésta puede quedar mitigada por su relación $\mathrm{C} / \mathrm{N}$, que es superior a la que presentan las bacterias (Wild, 1992). 
Las dimensiones de los hongos oscilan entre el nivel microscópico y los visibles a simple vista. Los pequeños son los más numerosos y a menudo contribuyen, más que cualquier otro microorganismo, al peso de la materia orgánica en el suelo (Thompson y Troeh, 1988). Algunos hongos pueden sintetizar compuestos polifenólicos, que se parecen a las formas encontradas en la fracción húmica del suelo, contribuyendo de esta manera a la formación de la materia orgánica evolucionada y estable. Generalmente toleran mejor las situaciones ácidas y el escaso suministro de calcio que otros microorganismos, y su presencia cuantitativa en los suelos ácidos es del mismo orden que en los neutros y suelen predominar en la población microbiana de los suelos forestales, porque los restantes microorganismos se hacen menos numerosos en condiciones ácidas. Además, los hongos disponen de diversos métodos para sobrevivir durante épocas desfavorables, como el calor y la sequía del suelo (producción de esporas en cuerpos fructíferos, clamidósporas, esclerotes, etc.). Por otro lado, la excesiva humedad suele ser desfavorable para ellos (Wild,1992).

La población fungosa predomina en suelos ricos en restos vegetales, donde la competencia por alimentos y energía no es demasiado aguda, pero declinan rápidamente cuando desaparecen los materiales fácilmente degradables; en cambio, las bacterias persisten más tiempo y consumen a los hongos (Thompson y Troeh, 1988). La posibilidad de que predominen los hongos o el grupo bacteriasactinomicetos depende de las condiciones locales, especialmente del $\mathrm{pH}$ y del contenido de humedad. Además, los mecanismos por los que los fragmentos de hifas y especialmente las conidias de los hongos no germinan o son estimulados al crecimiento, son complejos y en cierto modo aún falta aclarar. Para describir este efecto, se usa el término fungistasia edáfica y se apoya en dos hipótesis: la primera, atribuía la disminución de la germinación de las esporas a la ausencia de nutrientes en el suelo, mientras que la segunda postulaba la presencia de inhibidores fúngicos en el suelo. Esta última, inicialmente no fue tenida muy en cuenta, pero después se reveló la existencia de inhibidores volátiles de origen microbiano como el etileno (Wild, 1992).

La abundancia y actividad de los microorganismos del suelo pueden estar influenciadas por la actividad de la fauna del suelo, como ocurre en las praderas (Bardgett et al., 1993). De las interacciones que ocurren en el suelo, la que existe entre la microbiota y los invertebrados es una de las más relevantes (Vink y Van Straalen, 1999). Además de los diferentes grupos que constituyen la fauna del suelo, los nematodos son los más abundantes, calculándose que existen entre 1,8 y 120 millones $/ \mathrm{m}^{2}$ (Kevan, 1970). Estos microorganismos presentan una gran plasticidad $y$, por tanto, una gran adaptabilidad que les ha llevado a desarrollar diferentes funciones dentro del suelo, basadas fundamentalmente en su hábito alimentario $\mathrm{y}$, por consiguiente, en el lugar que ocupan a lo largo de la cadena trófica. Generalmente se clasifican en especies bacteriófagas, micófagas, depredadores y fitófagas (Zancada y Sánchez, 1994).

Existen métodos que permiten estimar la intensidad de la actividad biológica en el suelo. Diferentes sustratos han sido usados como material modelo para medir la actividad de descomposición en el suelo (Velich et al., 1968, Pokorná and Novák 1981, Rychnovská 1987). Así, Velich et al. (1968) utilizaron una proteína animal regenerada (cutizina) para evaluar la intensidad de la descomposición del nitrógeno orgánico y la actividad proteolítica del suelo. Rychnovská (1985) menciona los resultados de Úlehlová y Hundt, quienes usaron celulosa (papel filtro) como sustrato y midieron la velocidad de la descomposición de ésta en diferentes tipos de asociaciones vegetales, hallando que la actividad celulolítica se incrementaba principalmente con la productividad de la vegetación, siendo a su vez dependiente de la humedad, temperatura y tipo de suelo (Stanton 1988). Velich (1986) utilizó ambos sustratos en el Test de Cutizina y Celulosa (Figura 1) para evaluar la intensidad de la actividad celulolítica y proteolítica de los microorganismos en el suelo. En este Test, los sustratos de celulosa (papel filtro) y proteína (cutizina) son depositados en una bolsa de malla de PVC para luego ser enterrados a una profundidad de 100 mm. Después de un tiempo determinado de exposición, las pruebas son recuperadas del suelo, y los sustratos son procesados en laboratorio. La tasa de descomposición de celulosa y cutizina (mg/g/día) es calculada según la ecuación de Wiegert y Evans (Meneses, 2005).

Otra forma de estimar la población microbiana del suelo es usando el llamado Método de diluciones sucesivas (Figura 2), que consiste en tomar una muestra de suelo, la cual se seca al medio am- 

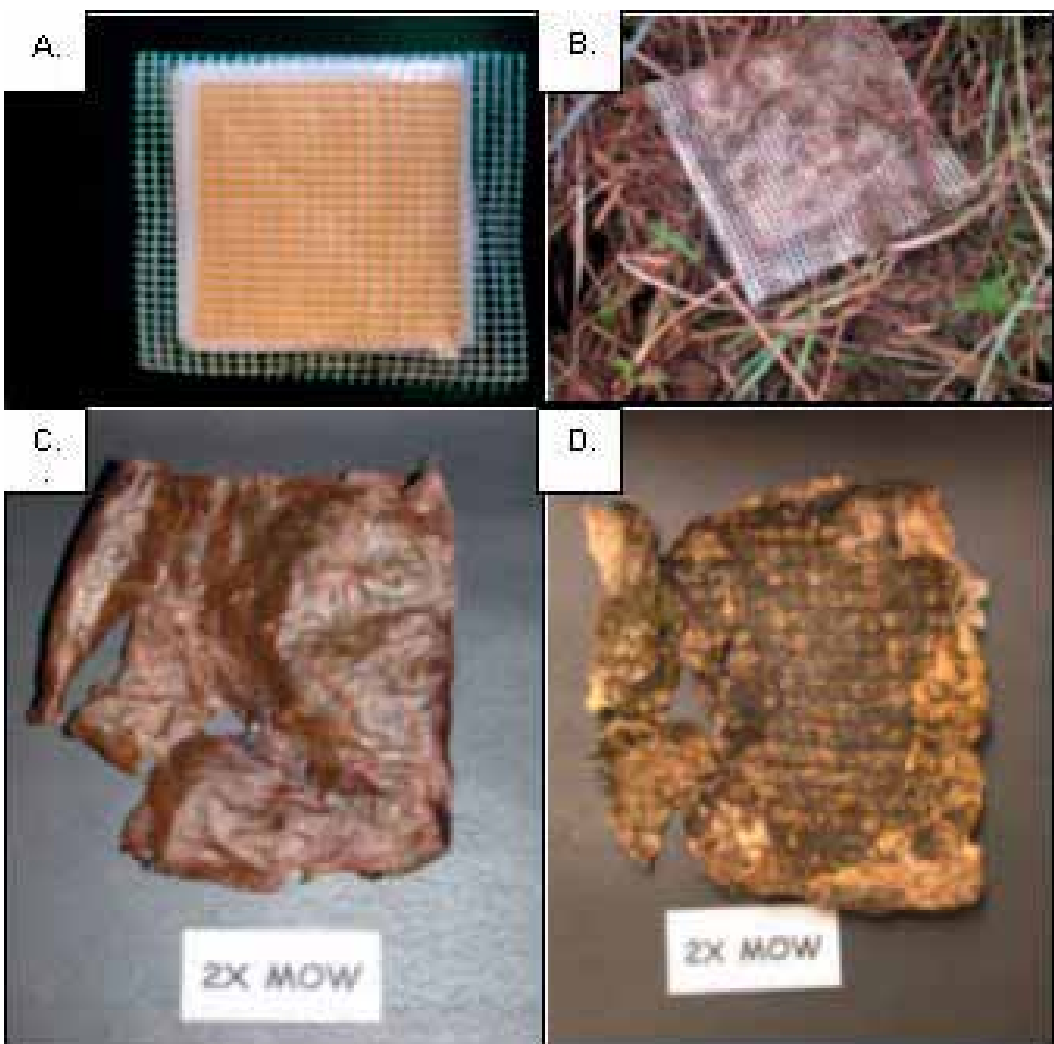

D.

Figura 1. Test de cutizina y celulosa A. Bolsas de malla conteniendo papel filtro y cutizina. B. Bolsas de malla recuperadas del suelo. C. Cutizina después de haber sido procesada en laboratorio. D. Papel filtro después de haber sido recuperado del suelo.

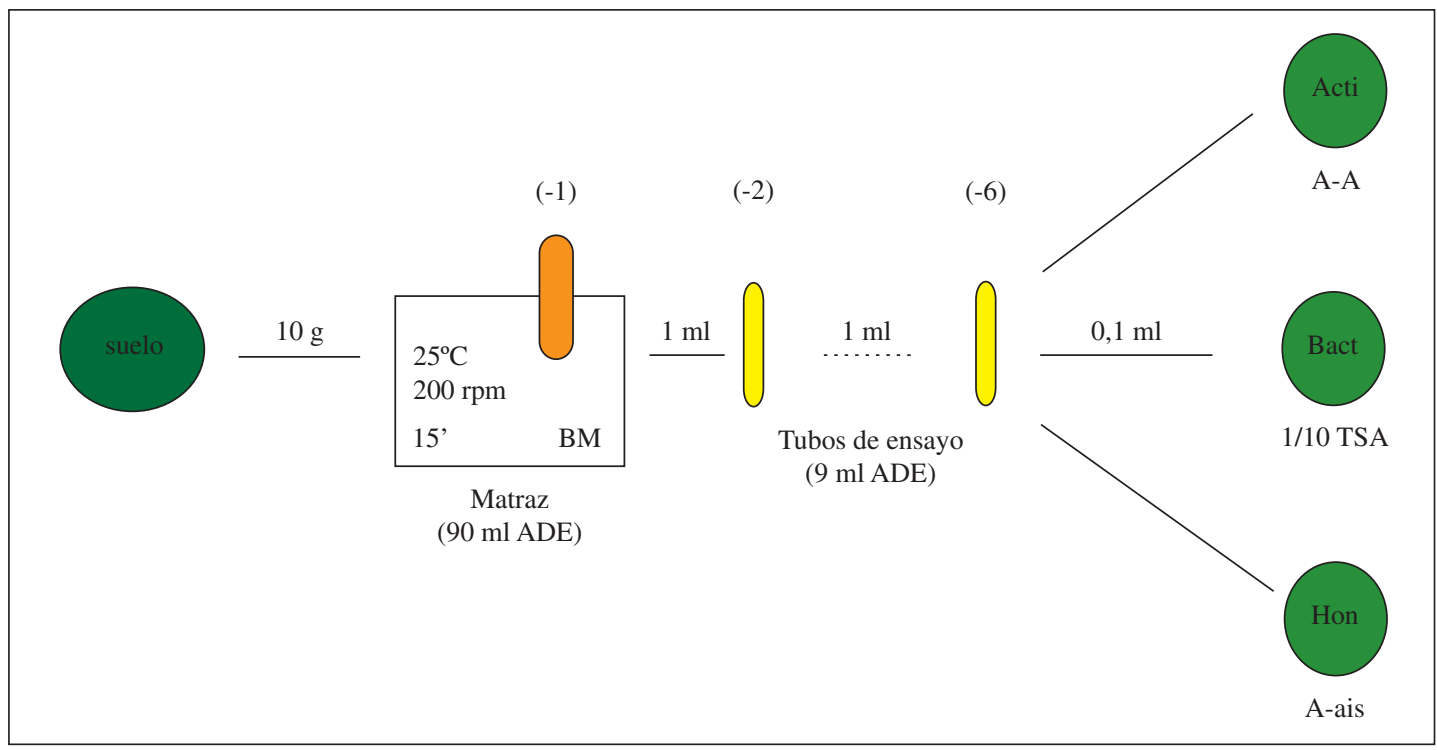

Figura 2. Esquema del Método de diluciones sucesivas para estimar la población microbiana del suelo. Para cultivar los actinomicetos se emplea el medio Agar-Agua (A-A), para bacterias el 1/10 de TSA (1/10 de TSA ) y para hongos el denominado AgarAislamiento (A-Ais). 
biente y se diluye en agua destilada estéril de forma sucesiva hasta llegar a la más baja concentración. De esta última suspensión se toman alícuotas que se cultivan en medios de cultivos específicos para cada microorganismo.

Los métodos cuantitativos y cualitativos de estimación de la actividad microbiana del suelo pueden ser complementarios. Esto debido a que la cantidad de tejido microbiano o biomasa no debe considerarse como una medida de actividad, pues muchas células microbianas pueden estar vivas, pero aletargadas. Por lo tanto, la actividad biológica del suelo no es un concepto que se pueda definir fácilmente en términos cuantitativos (Wild, 1992).

\section{ALGUNOS FACTORES QUE AFECTAN A LOS MICROORGANISMOS EN EL SUELO}

El suelo es un medio muy complejo, donde se dan innumerables interacciones que afectan las poblaciones de los organismos que la habitan. Asimismo, los factores medioambientales pueden afectar directa o indirectamente las poblaciones microbianas. Así tenemos que el contenido de humedad del suelo influye en la actividad de la población microbiana de diferentes maneras, ya que a medida que se va secando el agua, las películas se hacen más finas y afectan la disponibilidad del agua y las relaciones osmóticas de las células. Las bacterias (aunque muchas midan menos de $1 \mu \mathrm{m}$ de diámetro) parecen tener fácil motilidad en películas sensiblemente más gruesas a $1 \mu \mathrm{m}$, independientemente de que puedan desarrollarse con una humedad más baja. En cambio, los hongos filamentosos y en menor proporción los actinomicetos, difieren de las bacterias en que sus hifas no necesitan crecer en una película continua de agua sino que pueden atravesar espacios abiertos al aire y pueden realizar sus funciones en condiciones más secas que las bacterias (Wild, 1992).

Los actinomicetos son menos numerosos que las bacterias y uno de los factores favorables para su presencia es la abundancia de calcio, que proporciona una condición neutra o ligeramente alcalina (Thompson y Troeh, 1988). Otro factor importante a tener en cuenta es la humedad; aunque los actinomicetos necesitan humedad para su crecimiento, sus esporas pueden soportar prolongadas sequías durante más tiempo que otros microorganismos, hasta el punto que puedan llegar a dominar la población edáfica (Wild, 1992). Meiklejon (1957) registró un aumento espectacular de la proporción de actinomicetos en aislamientos obtenidos de un suelo de Kenia que había sufrido una sequía muy severa. Efectos similares se observaron en el sur de Inglaterra, después de años muy secos (Wild, 1992).

Otro factor importante es la temperatura, ya que la actividad metabólica de los organismos se inicia cuando se supera un determinado umbral térmico, aumenta a medida que las temperaturas se elevan hasta un cierto valor máximo y finalmente se reduce rápidamente cuando las temperaturas superan este valor (Wild, 1992). Pietikainen y Fritze (1993) evaluaron la actividad de la biomasa microbiana en la capa de humus de residuos de hojas, recuperado de un bosque de pinos y sometido a tratamientos de "incendio controlado" e "incendio forestal simulado". El primero fue más intenso que el segundo tratamiento, situación que se vio reflejada en todas las evaluaciones tomadas. En las parcelas de "incendio controlado", los niveles de $\mathrm{C}, \mathrm{N}$ y $\mathrm{CO}^{2}$ fueron menores que en las parcelas testigo, pero en las parcelas de "incendio forestal simulado", los niveles de $\mathrm{C}, \mathrm{N}$ y $\mathrm{CO}^{2}$ prácticamente no cambiaron con respecto a sus parcelas testigo.

$\mathrm{El} \mathrm{pH}$ puede tener importancia en la retención de las bacterias en el suelo, según lo observado experimentalmente por Bitton et al. (1974). La mayor parte de bacterias y actinomicetos se desarrollan mejor a pH neutro y ligeramente alcalino; en cambio, los hongos se desarrollan a un pH más amplio (Fassbender, 1982). También existe la posibilidad que la materia orgánica por su carga negativa, adsorba y retenga a estos microorganismos de manera significativa (Goyal y Gerba, 1979). Dighton et al. (1997) señalan que los factores abióticos del suelo pueden tener un papel importante en la dispersión de los microorganismos del suelo.

La aplicación de vapor o productos químicos al suelo producen inicialmente un descenso del número de los organismos que componen su población, seguido de un rápido aumento del número de bacterias una vez que ha pasado la acción de la esterilización. Los protozoos se recuperan más lentamente y cuando el tratamiento se hace con vapor, el restablecimiento de los hongos suele ser muy lento; pero este tratamiento puede producir efectos fitotóxicos, aunque no suelen ser tan severos como los que pueden originarse con calor seco, que nunca debe recomendarse (Wild, 1992). 
Según Barberá (1989), los desinfectantes del suelo actúan sobre una gran generalidad de seres vivos y los nemátodos, hongos e insectos predadores (que viven y se alimentan de otros parásitos o son saprofitos), quedan igualmente afectados por su acción. Hay también un efecto sobre las bacterias; las más afectadas son las nitrificantes, en tanto que las poblaciones de amonificantes se recolonizan rápidamente. Por eso es necesario que cuando se evalúa el efecto de los pesticidas sobre los microorganismos, debe considerarse la estructura de las poblaciones y la actividad de éstas. Van Beelen y Doelman (1997) señalan que varias pruebas de toxicidad microbiana no revelan la verdadera sensibilidad de los microorganismos, porque no consideran el reemplazo de las especies susceptibles por otras más resistentes. Los pesticidas organofosforados, como el Diazinon, reducen la respiración, la actividad de la deshidrogenasa y la nitrificación del suelo (Vink y Van Straalen, 1999).

Hemos mencionado la necesidad de trabajar en el manejo ecológico del suelo como una herramienta importante de la agricultura orgánica. Dentro de esta tarea se busca actuar sobre las parcelas agrícolas de tal forma que permitan un aumento del contenido de la materia orgánica, lo cual a su vez tendría un efecto positivo sobre la biología del suelo. Bloem (1994) ha señalado que para reducir las pérdidas y facilitar el uso óptimo del $\mathrm{N}$ mineralizado por el cultivo en crecimiento, es necesario conocer el efecto del manejo de las fincas sobre los organismos del suelo y el ciclo del nitrógeno. Además, estos efectos ayudarían a reducir los problemas ambientales, porque permitirían una reducción considerable de la fertilización nitrogenada, debido a una alta mineralización del N, desde la materia orgánica.

En Alemania, Vonlutzow y Ottow (1994) compararon la influencia que ejerce la agricultura convencional y la biológica sobre la biomasa microbiana, indicando que al inicio de la primavera y otoño de 1990 el carbono orgánico y el nitrógeno total fueron ligeramente menores en las parcelas con agricultura convencional. En cambio, durante el período con vegetación, el $\mathrm{C}$ orgánico y el $\mathrm{N}$ total se incrementaron continuamente en ambos sistemas, aunque en parcela manejada convencionalmente el incremento fue mayor.

El mismo Bloem (1994) ha estudiando el efecto de un sistema de manejo convencional y un integrado sobre los organismos del suelo en el cultivo de trigo. Los resultados demostraron que la biomasa fungosa fue casi 100 veces menor que la biomasa bacteriana, pero esta última no fue significativamente más alta en el sistema de manejo integrado. En cambio, las poblaciones de amebas y los nemátodos sí fueron más altas en la parcela de manejo integrado, en 64 y $22 \%$, respectivamente. Cuando se midió la mineralización del $\mathrm{N}$, ésta fue $30 \%$ más alta con manejo integrado, diferencia que fue atribuida al $30 \%$ más de materia orgánica encontrada en dicha parcela.

En Australia, Pankhurst (1995) realizó dos pruebas de campo de largo período para detectar cambios en las propiedades biológicas del suelo, como consecuencia de variaciones en el manejo agrícola, y encontró que la labranza, la aplicación de rastrojos, la rotación o no de cultivos (trigo-trigo, trigo-pasto) y la fertilización nitrogenada (80 $\mathrm{kg} / \mathrm{ha}$ ) afectaron significativamente la mineralización del $\mathrm{C}$ y la biomasa microbiana. También observó que la labranza con el manejo de rastrojos afectó significativamente a los hongos patógenos de raíces, a los protozoos, colémbolos, lombrices y la descomposición de la celulosa. La rotación de cultivos afectó a los hongos micorríticos, los protozoos y la actividad peptidasa del suelo. La fertilización con $\mathrm{N}$ tuvo un efecto significativo sobre los hongos micorríticos, protozoos y descomposición de la celulosa.

Asimismo, cuando Ferris (1996) evaluó las comunidades de nemátodos en el cultivo de tomate en parcelas manejadas de manera convencional y orgánica, encontró que durante el período de descomposición de la materia orgánica los nemátodos micófagos fueron más abundantes en las parcelas convencionales que en las orgánicas; mientras que las poblaciones de nemátodos predadores y omnívoros fueron bajas en ambos sistemas agrícolas.

Dos años más tarde, en California (EE.UU.), Jaffee et al. (1998) evaluaron los hongos atrapadores de nemátodos, los nemátodos y la biomasa microbiana, en parcelas de campo manejadas orgánica y convencionalmente. El número de especies de hongos atrapadores de nemátodos fue significativamente mayor en parcelas orgánicas, y dos especies (Arthrobotrys dactyloides y Nematococcus leiosporus) fueron detectadas más frecuentemente en parcelas orgánicas y en mayores poblaciones. En cambio, otras dos especies (A. haptotyla y A. thaumasia) tendieron a ser más numerosas en par- 
celas convencionales y la densidad total de los hongos nematófagos fue similar en ambos sistemas. Los nemátodos bacteriófagos fueron más abundantes en parcelas orgánicas y también la biomasa microbiana. Sin embargo, en un bioensayo, la supresión de Meloidogyne javanica no tuvo relación con el sistema de manejo o con la densidad poblacional de los hongos atrapadores de nemátodos, aunque sí estuvo relacionada positivamente con la biomasa microbiana.

El número y la actividad de los microorganismos están controlados parcialmente por la cantidad de energía que pueda liberarse en la descomposición de la materia orgánica, y no importa cuántas etapas o qué organismos intervienen en su degradación. En consecuencia, ningún factor que influya en la biología del suelo puede incrementar el número de individuos heterótrofos, si no aumenta el nivel del sustrato energético. Por lo tanto, si un grupo aumenta, otros deben necesariamente disminuir. Sin embargo, en ensayos donde se realizaron aportes de materia orgánica al suelo y se obtuvieron diferentes flujos de energía, las poblaciones microbianas no presentaron diferencias notables, pero sí en los protozoos, que por ser depredadores requieren un nivel trófico más elevado (Wild, 1992). Algunos autores como Vallini et al. (1993) han encontrado que el uso de ácidos húmicos incrementó la población de actinomicetos y de bacterias aeróbicas, en la rizósfera del laurel.

\section{EXPERIENCIAS DEL USO DE MATERIA ORGÁNICA EN EL SUELO}

El nivel de consumo de las sociedades actuales ha incrementado la producción de desechos orgánicos que de no procesarse adecuadamente aumenta el riesgo de contaminación al hombre y el medio ambiente. Según Navarro-Pedreño et al. (1995), América Latina produce anualmente 3,3 billones de residuos que podrían crear problemas de contaminación, especialmente de los ríos. Por ello la importancia de revisar las experiencias que permitan el uso de dichos residuos en la agricultura.

Abad (1993) señala que los ácidos húmicos y fúlvicos tienen un efecto positivo sobre muchas funciones de la planta, a nivel de células y órganos; por su parte, Kononova (1970) señala el efecto estimulante de los ácido húmicos y los fulvoácidos en la formación de raíces al acelerar la diferenciación del punto de crecimiento. Warman (1998) encontró que los suelos fertilizados convencionalmente son generalmente altos en $\mathrm{P}$ y K, mientras que los suelos fertilizados con compost tienen un mayor contenido de $\mathrm{C}, \mathrm{Ca}, \mathrm{Mg}, \mathrm{Mn}, \mathrm{Cu}$ y $\mathrm{Zn}$.

También se ha evaluado el efecto de la materia orgánica o de productos derivados de ésta, sobre el crecimiento de la planta o la producción de los cultivos. Buniselli et al. (1990) encontraron un aumento del peso y altura de la planta, longitud de la mazorca y rendimiento de grano en maíz, cuando aplicaron 100, 300 y $900 \mathrm{~kg} / \mathrm{ha}$ de residuos sólidos urbanos (RSU) compostados, junto con aplicaciones complementarias de NPK. De la misma manera, Climent et al. (1990), al añadir 18 y 36 t/ha de RSU compostado y con una relación $\mathrm{C} / \mathrm{N}$, corregida con la aplicación de fertilizante nitrogenado mineral, lograron incrementar el rendimiento de papa en un $25 \%$ con relación al control.

Otros investigadores, como Lungu (1993), trabajaron con estiércol de granja solo y mezclado con limo, para evaluar su efecto sobre el crecimiento del maíz, el pH del suelo y el aluminio intercambiable en un suelo ácido con un $\mathrm{pH}$ inicial de $3,9-4,3$ y $1,3 \mathrm{cmol} / \mathrm{kg}$ de aluminio intercambiable. El limo (3-6 t/ha) fue aplicado solamente al inicio de la campaña, mientras que el estiércol de granja (30 t/ha) se aplicó durante toda la campaña. Los resultados demostraron que las más altas reducciones de aluminio intercambiable y el incremento del pH de la capa arable del suelo, en una unidad, se obtenían con la aplicación del estiércol solo o en combinación con 3 t/ha de limo. Igualmente, el crecimiento y la producción se incrementaban significativamente con estiércol solo o mezclado con limo.

Keeling (1994) aplicó compost derivado de basura doméstica sobre ryegrass y encontró que la fracción del compost con compuestos de alto peso molecular tuvo propiedades que estimularon el crecimiento de la planta, mientras que la fracción de bajo peso molecular causaba fitotoxicidad. Tan (1994), al evaluar la interacción ácidos húmicosapatita y su disponibilidad para el crecimiento del maíz, encontró las mayores cantidades del ion fosfato a un pH de 5, en comparación con un pH de 7, y los mejores resultados en el crecimiento de la planta se lograron con apatita + ácidos húmicos en un $\mathrm{pH}$ de 5.

En España, Hernández (1996) trabajó con substancias húmicas extraídas de residuos municipales 
(lodos de aguas residuales y un compost) y otras provenientes de materiales más humidificados (leonardita, turba y un ácido húmico comercial) para conocer su efecto sobre la planta y la absorción de nutrientes en un cultivo hidropónico de cebada, encontrando que el efecto de ambos grupos de substancias húmicas fue similar, tanto en el crecimiento como en la absorción de nutrientes. Las dosis de $10 \mathrm{mg}$ de $\mathrm{C} / \mathrm{l}$ favorecieron el crecimiento de las plantas, mientras que las dosis más altas a veces lo inhibieron. También señaló que las substancias húmicas favorecieron más el desarrollo de la parte aérea que el de la raíz. La absorción de macronutrientes $(\mathrm{N}, \mathrm{P}, \mathrm{K})$ fue significativamente afectada por la adición de substancias húmicas, pero diferente para cada uno de los nutrientes. La absorción de nitrógeno, por ejemplo, fue estimulada por las dosis más bajas, ocurriendo lo contrario al incrementar las dosis. En el caso de los micronutrientes, la absorción también fue mayor con las dosis más bajas, mientras que las dosis mayores a $10 \mathrm{mg}$ de carbono/L lo inhibieron. Esto probablemente fue una de las causas de la depresión del crecimiento observado con las dosis más altas.

Chung (1997) evaluó el efecto del compost de mazorca de maíz con limo en un suelo rojo, ácido ( $\mathrm{pH}=4,05)$, sobre el crecimiento de tres especies (lechuga, guisante y maíz), las cuales fueron seleccionadas por su tolerancia variable a la acidez del suelo. Las enmiendas aplicadas al suelo fueron: 1,2 y $4 \mathrm{cmol}$ de carbonato cálcico/ $\mathrm{kg}$ de suelo; 5,10 y 20 g de compost de mazorca de maíz/kg de suelo. Los resultados mostraron un mayor contenido de manganeso que de aluminio en los brotes de todas las plantas evaluadas, al margen de su tolerancia a la acidez o del tratamiento. También observó que el limo fue más efectivo, en comparación al compost, para reducir el contenido de manganeso en los brotes. Sin embargo, el contenido de fósforo en los brotes se incrementó con el compost, a partir de un aumento en el contenido de materia orgánica. Igualmente, el compost incrementó significativamente el peso seco de los brotes; por encima de los valores obtenidos con limo. En cambio, Young (1997), trabajando con ácidos húmicos purificados, encontró un efecto significativo en el crecimiento radicular de plántulas de lechuga, pero no de los brotes.

En Italia, Pinamonti (1998), usando compost como mulch en viñedos, encontró un incremento del contenido de materia orgánica, de fósforo disponible y del potasio de cambio en el suelo; también mejoró la porosidad y la capacidad de retención del agua. Las plantas de vid mostraron un aumento en la concentración de K en hojas, pero una disminución en el nivel de P, Ca y Mg. El contenido de N, Fe y Mn no cambió significativamente durante el experimento. El crecimiento de las plantas mejoró durante el primer año, pero decreció con el tiempo y la producción de uva sólo fue significativamente mayor el primer año de evaluación. El potasio total y el ácido tartárico del mosto aumentaron significativamente, pero los otros parámetros evaluados no manifestaron cambios significativos.

En un ensayo similar al anterior en viñedos jóvenes en Australia, Buckerfield y Webster (1998) encontraron que el diámetro del tronco y la longitud de brotes fueron mayores cuando había mulch de compost. También la producción de uva se incrementó considerablemente, los grados brix aumentaron ligeramente, pero no hubo cambios significativos en el pH del zumo y en la acidez titulable.

En Alicante, Navarro (1992) evaluó el efecto del lodo de depuradora de una planta de tratamiento de aguas residuales en el cultivo de tomate. El lodo fue secado y estabilizado durante cinco meses y luego fue aplicado en un suelo calizo a una dosis de $0,5 \mathrm{~kg} / \mathrm{m}^{2}$. Se obtuvo un incremento en el número de frutos en un $56 \%$ y el peso de frutos/ planta en casi un $63 \%$. También en tomate, Brito et al. (1995) estudiaron el efecto de cuatro compost comerciales sobre el crecimiento, la microflora total y la incidencia de las rizobacterias en la rizósfera de la planta. Encontraron que tres de los compost usados mejoraron significativamente el crecimiento de la planta, mientras que uno (el restante) lo disminuyó también significativamente. Las enmiendas solamente causaron pequeñas variaciones en el número total de bacterias, actinomicetos y hongos de la rizósfera.

Algunos investigadores han visto la posibilidad de usar materiales de origen marino. Este es el caso de Sarathchandra et al. (1996), en Nueva Zelandia, quienes aplicaron al suelo una enmienda en base a quitina de caparazón de cangrejo y encontraron que, en el suelo con enmienda, el peso de los brotes y raíces del ryegrass perenne (Lolium perenne) fue mayor con relación al testigo sin tratar, probablemente debido al aumento del $\mathrm{N}$ mineralizado de la enmienda, aunque la relación raíces/ brotes fue menor en plantas tratadas. Por otro lado, 
cuando la enmienda fue aplicada en trébol blanco (Trifolium repens), observaron una reducción en el número de nódulos bacterianos en plantas de 12 y 42 días, y también en el peso de brotes y raíces, a los 42 días, posiblemente debido a efectos fitotóxicos de la enmienda, pero, en este caso, la relación raíces/brotes fue mayor en plantas tratadas. Las poblaciones de bacterias y hongos del suelo aumentaron significativamente en los tratamientos con la enmienda.

En Perú también existen muchos casos de uso de materia orgánica a nivel vivero y en campo, tanto con cultivos de costa como de sierra y selva. Pero la experiencia comercial más importante ocurre en Chavimochic, una zona productora de hortalizas y frutales en la costa norte de Perú, donde se usan 100 a 120 t/ha/año (Figura 3). Esto muestra la aceptación de una tecnología antigua, pero que ha sido retomada y va ganando cada vez más adeptos que buscan desarrollar sistemas agrícolas más sostenibles.

Una variante interesante sobre el uso de la materia orgánica ocurre en Almería, al sureste de España, en los invernaderos para la producción de hortalizas, donde se usa como substrato un sistema llamado "Enarenado" que considera una capa de materia orgánica que se ubica entre el suelo agrícola y una capa de arena (Figura 4). Este sistema permite una mayor retención de la humedad y una lenta filtración del agua la que estará más disponible para la planta. En Australia se ha reportado el uso de pellets de materia orgánica en forma de mulch; con ese tratamiento el contenido de humedad del suelo en viñedos fue mayor en un $30 \%$ debido a que se reducen las pérdidas de agua por evaporación (Buckerfield y Webster, 1999).

Los resultados favorables que se obtienen cuando se aplican materiales orgánicos sobre las

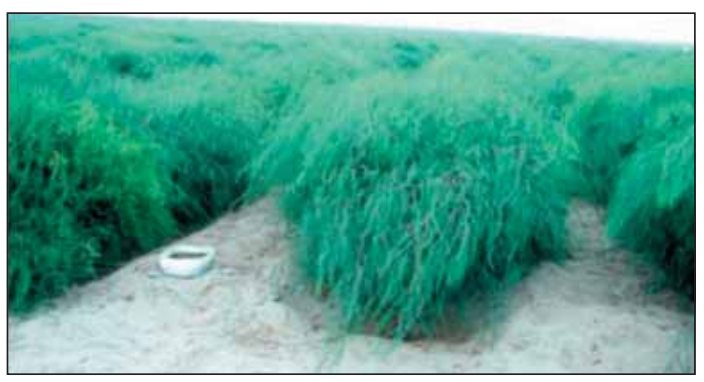

Figura 3. Cultivo de espárrago en zona de irrigación Chavimochic, costa norte del Perú. plantas han sugerido la necesidad de intentar explicar mejor las razones de este efecto. Young (1997) señaló que se ha demostrado que los ácidos húmicos contienen muchos tipos de compuestos nitrogenados. Además, aisló a partir del suelo y de substancias húmicas de diversas procedencias las poliaminas, que son compuestos que funcionan como reguladores de crecimiento de las plantas, por lo que sugirió que su presencia en las substancias húmicas podría explicar la actividad parecida a hormonas de dichas substancias.

Otra substancia que también podría estar involucrada es el etileno. Este regulador del crecimiento vegetal es producido por las plantas y los microorganismos del suelo (Tang, 1993). En este sentido, se ha encontrado un aumento significativo del etileno cuando aplicó residuos de corral de aves, compostados y no compostados, sobre suelos del oriente de Arkansas y bajo condiciones de inundación. La mayor producción de etileno por gramo de $\mathrm{C}$ adicionado la obtuvo con el material no compostado, lo cual podría explicarse por las diferencias en la biodisponibilidad del C en los dos materiales evaluados (Tang, 1993).

Sin embargo, a pesar de la información favorable al empleo de materiales orgánicos, éstos siempre deben ser usados con prudencia y teniendo en cuenta todas las consideraciones pertinentes, ya que, por ejemplo, Cegarra et al. (1983) señalan que los, residuos vegetales, cuando son añadidos a los suelos, pueden requerir de aporte suplementario de $\mathrm{N}$ para que los procesos de mineralización se desarrollen adecuadamente. Esto sucede como consecuencia de la elevada relación $\mathrm{C} / \mathrm{N}$ que posee el residuo. Por ello, un riesgo que se puede plantear es la demanda inicial de nutrientes para activar los procesos biológicos que actúan sobre los restos de cosecha adicionados.

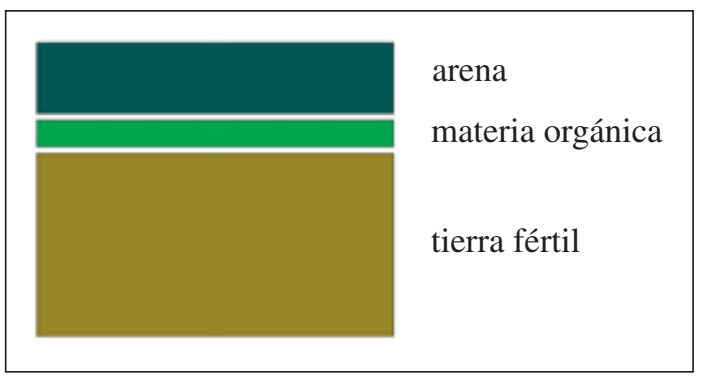

Figura 4. Esquema del sistema de "enarenado", substrato usado para la producción de hortalizas en Almería, España. 
Al fenómeno descrito en el párrafo anterior se le denomina inmovilización y ocurre lo contrario a la nitrificación, es decir, el nitrógeno inorgánico pasa a orgánico, debido a que numerosos microorganismos utilizan el nitrógeno mineral del suelo para la síntesis de sus propias macromoléculas, compitiendo directamente con las plantas cultivadas (Gros y Domínguez, 1992). Zeng et al. (1993) tuvieron este problema cuando aplicaron altos niveles de leño de corral, como enmienda de suelo, en trabajos de campo y en parcelas con Medicago sativa y Dactylis glomerata. En ambos casos, el crecimiento de la planta disminuyó cuando aumentó la cantidad de leño, material que inmovilizó el nitrógeno y redujo su disponibilidad para las plantas. En las parcelas, ambas especies tuvieron una baja producción en la primera cosecha, pero ésta fue mucho más alta en la segunda cosecha, indicando que la inmovilización del nitrógeno decrece con el tiempo. Además, observaron que en parcelas mejoradas con leño, el crecimiento de M. sati-

\section{LITERATURA CITADA}

ABAD, M., 1993. Características y propiedades. En: Cultivos sin suelo curso superior de especialización. Editor F. Canovas Martínez \& J. Díaz Álvarez. FIAPA. Almería, pp. 47-62.

ANÓNIMO, 1988. Manual de fertilidad de suelos. Potash \& Phosphate Institute. Georgia. USA, 85 p.

ARENS, P. L., 1983. En: El reciclaje de materias orgánicas en la agricultura de América Latina. FAO. Roma. Italia.

ÁlVAREZ, M. A., GAGNE, S. Y ANTOUN, H., 1995. Effect of compost on rhizosphere microflora of the tomato and on the incidence of plant growth-promoting rhizobacteria. Applied and Environmental Microbiology. 61 (1), 194-199.

BARBERÁ, C., 1989. Pesticidas agrícolas. 4ta. edición. Omega S. A. Barcelona, 603 p.

BARDGETT, R. D., FRANKLAND, J. C. Y WHITTAKER, J. B., 1993. The effects of agricultural management on the soil biota of some upland grasslands. Agriculture Ecosystems and Environment 45, 25-45.

BITTON, G., LAHAV, N. Y HENIS, Y., 1974. Movement and retention of Klebssiella aerogenes in soil columns. Plant and Soil 40, 373-380.

BLOEM, J., 1994. Dynamics of microorganisms, microbivores and nitrogen mineralisation in winter wheat fields under conventional and integrated management. Agriculture Ecosystems and Environment 51 (1-2), 129-143.

MA DE BRITO ÁLVAREZ, S. GAGNE AND H. ANTOUN, 1995. Effect of compost on Rhizosphere Microflora of the tomato and on the Incidence of Plamt Growth-Promoting Rhizobacteria. Appl. Environ. Microbiol., Jan 1995, 1994199, Vol. 61, $\mathrm{N}^{\mathrm{o}} 1$. va fue superior al de D. glomerata, debido a su capacidad para fijar N. El leño proporcionó nutrientes minerales y materia orgánica al suelo, disminuyó la densidad del suelo y también mejoró sus propiedades para retener la humedad. Los problemas causados por la inmovilización del $\mathrm{N}$ han llevado a algunos autores como Hernández et al. (1983) a no recomendar la siembra durante el período de mineralización más acentuado, con el fin de evitar que se produzcan necesidades de nitrógeno para la planta debido a la competencia estrecha por este nutriente entre los microorganismos y el vegetal cultivado.

Otro proceso microbiano a tener en cuenta es la denitrificación, que consiste en el paso (reducción) de los nitratos al estado de productos gaseosos $\left(\mathrm{N}_{2} \mathrm{O}\right.$ y $\left.\mathrm{N}_{2}\right)$, que son susceptibles de volatilizarse y perderse en la atmósfera. Lo realizan bacterias anaeróbicas, que usan el nitrato para su respiración, en reemplazo del oxígeno que falta en el suelo (Gros y Domínguez, 1992).

BUSINELLI, M., GIGLIOTTI, G. Y GIUSQUIANI, P. L., 1990. Applicazione del compost da RSU in agricultura. I: effetto sulla produttività del mais e desino dei nutrienti e dei metalli pesanti nel terreno. Agrochimica 35 (1-2-3), 13-25.

BUCKERFIELD, J. Y WEBSTER, K., 1998. Compost as mulch for managing young vines. The Australian Grapegrower and Winemaker. October, pp. 75-78.

BUCKERFIELD, J. Y WEBSTER, K., 1999. Pellets for soil improvement at planting. The Australian Grapegrower and Winemaker. October, pp. 31-33.

BRENES, L. 2003. Producción orgánica: algunas limitaciones que enfrentan los pequeños productores. Manejo Integrado de Plagas y Agroecología 70: 7-18.

CEGARRA, J., HERNÁNDEZ, T. Y COSTA, F., 1983. Adición de residuos vegetales a suelos calizos.V. Influencia sobre el desarrollo vegetal. Anales de Edafología y Agrobiología 42 (3-4), 545-552.

CLIMENT, M. D., ARAGÓN, P., ABAD, M. Y ROSELLÓ, M. V., 1990. Utilización del compost de residuos sólidos urbanos como enmienda orgánica en agricultura. Actas 1er. Congreso Internacional de Química de la ANQUE 1, 171-180. Tenerife.

CREMLYN, R. J., 1991. Agrochemicals preparation and mode of action. John Wiley \& Sons Ltd. England, 396 p.

CHUNG, R. S., 1997. Effect of corncob compost on plant growth in an acid soil. Communications in Soil Science and Plant Analysis 28 (9-10), 673-683.

DIGHTON, J., JONES, H., ROBINSON, C. Y BECKETT, 1997. The role of abiotic factors, cultivation practices and soil fauna in the dispersal of genetically modified microorganism in soils. Applied Soil Ecology 5: 109-131. 
FASSBENDER, H. 1982. Química de Suelos con énfasis en suelos de América Latina. 3ra reimpresión. IICA San José, Costa Rica. 422 p.

FERRIS, H. 1996. Dynamics of nematode communities in tomatoes grown in conventional and organic farming syste$\mathrm{ms}$ and their impact on soil fertility. Applied Soil Ecology. 3(2), 161-175.

GAN, J., YATES, S. R., CROWLEY, D. Y BECKER, J. O., 1998. Acceleration of 1,3-dichloropene degradation by organic amendments and potential aplication for emissions reduction. Journal of Environmental Quality 27, 408 - 414.

GAN, J., BECKER, J. O., ERNST, F., HUTCHINSON, CH., KNUTESON, J. A. Y YATES, S. R., 2000. Surface application of ammonium thiosulfate fertilizer to reduce volatilization of 1,3-dichloropene from soil. Pest Management Science 56, 264-270.

GOYAL, S. M. Y GERBA, C. P., 1979. Comparative adsorption of human enteroviruses, simian rotovirus and selected bacteriophages to soils. Applied Environment Microbiology 38, 241-247.

GRAETZ, H. A., 1997. Suelos y Fertilización. Traducido por: F. Luna Orozco. Trillas. México. $80 \mathrm{p}$.

GROS, A. Y DOMÍNGUEZ, A., 1992. Abonos guía práctica de la fertilización. 8va. edición. Ediciones Mundi-Prensa. Madrid. $450 \mathrm{p}$.

HERNÁNDEZ, T. 1996. Stimulation of barley growth and nutrients absorption by humic substances originating from various organic materials. Bioresource Technology 57 (3), 251-257.

JAFFEE, B. A., FERRIS, H. Y SCOW, K. M., 1998. Nematode-trapping fungi in organic and conventional cropping systems. Phytopathology 88, 344-350.

JHONSTOM, A. E. 1991. Soil fertility and soil organic matter. In: Advances in soil organic matter research: the impact on agriculture and the environment. Ed. The Royal Society of Chemistry. Cambridge. UK. pp. 299-314.

JUSTUS VON LIEBIG. 1843. En: Navarro Pedreño, J., Moral Herrero, Gómez Lucas y Mataix Beneyto., 1995. Residuos orgánicos y agricultura. Universidad de Alicante. Servicio de Publicaciones. $108 \mathrm{p}$.

KEELING, A. A., 1994. Germination and growth of plants in media containing unstable refuse derived compost. Soil Biology and Biochemistry 26 (6), 767-772.

KEVAN, D. K. MCE., 1970. The soil fauna its nature and biology. In: Ecology of soilborne plant pathogens. K. F. Baker and W. C. Snyder (Eds.). University of California Press. Berkeley. USA. pp. 187-209.

KONONOVA, M. M., 1967. Soil organic matter, its nature, its role in soil formation and in soil fertility. 2da edición. Pergamon Press. Oxford. $544 \mathrm{pp}$

LUNGU, O. I., 1993. Effects of lime an farmyard manure on soil acidity \& maize growth on an acid alfisol from Zambia. Tropical Agriculture 70 (4), 309-314.

MEIKLEJON, 1957. En: Wild, A. 1992. Condiciones del suelo y desarrollo de las plantas según Russell. Versión Española de P. Urbano Terrón y C. Rojo Fernández. MundiPrensa. Madrid. España, 1045 p.

MENESES, L. (2005). Effect of meadow management on plant species diversity, aboveground phytomass yield and sodding process. PhD Thesis. Czech University of Agriculture Pra- gue Faculty of Agronomy. Department of Forage Crops and Grassland Management.

MUSTIN, M., 1987. Le compost. Ed. François Dubusc. París, $954 \mathrm{p}$.

NAVARRO PEDREÑO, J., 1992. Estudio de los efectos de la salinidad y de la adición al suelo de residuos orgánicos en plantas de tomate. Tesis Doctoral. Facultad de Ciencias. Universidad de Alicante. Alicante. España.

NAVARRO PEDREÑO, J., MORAL HERRERO, GÓMEZ LUCAS Y MATAIX BENEYTO., 1995. Residuos orgánicos y agricultura. Universidad de Alicante. Servicio de Publicaciones. Alicante. España, 108 pp.

PANKHURST, C. E., 1995. Evaluation of soil biological properties as potential bioindicadores of soil health. Australian Journal of Experimental Agriculture 35 (7), 1015-1028.

PIETIKAINEN, J. Y FRITZE, H., 1993. Microbial biomass and activity in the humus layer following burning: shorteffects of two different fires. Canadian Journal of Forest Research 23, 1275-1285.

PINAMONTI, F., 1998. Compost mulch effects on soil fertility, nutritional status and performance of grapevine. Nutrient Cycling in Agroecosystems 51, 239-248.

POKORNA J. Y NOVAK B. (1981): Zprěsněná metodika biologického hodnocení půdy. In: Mikrobiální procesy v intenzivně využívanych orných půdach (závěrečná zpráva), VURV Praha - Ruzyně, $40 \mathrm{~s}$.

RYCHNOVSKA M. A KOL. (1985): Ekologie lučních porostů. Academia, Praha.

RYCHNOVSKÁ M. A KOL. (1987): Metody studiy travinných ekosystemů. Academia, Praha. $269 \mathrm{~s}$.

SARATHCHANDRA, S. U., WATSON, R. N. , COX, N. R., DIMENNA, M. E., BROWN, J. A., BURCH, G. Y NEVILLE, F. J., 1996. Effects of chitin of soil on microorganisms, nematodes and growth of white clover (Trifolium repens $\mathrm{L}$.) and perennial ryegrass (Lolium perenne $\mathrm{L}$.). Biology and Fertility of Soils. 22 (3), 221-226.

STANTON, N. L. (1988): The underground in grasslands. Ann. Rev. Ecol. Syst. 19:573-589.

TANG, T. J., 1993. Ethylene production in anaerobically incubated soils amendments with poultry litter. Soil Science 156 (3), 186-192.

TAN, K. H., 1994. The nature of humic acid-apatite interaction products and their availability to plant growth. Communications in Soil Science and Plant Analysis 25 (13-14), 2355-2369.

THOMPSON, L. M. Y TROEH, F. R., 1988. Los suelos y su fertilidad. Revert S.A. Barcelona. España, pp. 135-169.

VALLINI, G., PERA, A., AVIO, L., VALDRIGHI, M. Y GIOVANNETTI, M. 1993. Influence of humic acids on laurel growth, associated rhizospheric microorganisms and mycorrhizal fungi. Biology and Fertility of Soils 16, 1-4.

VAN BEELEN, P. Y DOELMAN, P., 1997. Significance and application of microbial toxicity tests in assesing ecotoxicological risks of contaminants in soil and sediment. Chemosphere 34: 41-51.

VANGESTEL, C. A. M., 1996. Phytotoxicity of some chloroanilines and chlorophenols in relation to bioavailability in soil. Water, Air and Soil Pollution 88 (1-2), 119-132.

VELICH J. (1986). Studium vývoje produkční schopností trvalých lučních porostů a drnového procesu prì dlouhodo- 
bého hnojení a jeho optimalizace. Disertační práce. VŠZ Praha, $420 \mathrm{~s}$

VELICH J., ŠTRAFELDA J., PRAJZLER J. Y BĚLOHOUBEK A. (1968): Vliv mineralního hnojení na biologickou aktivitu luchních půd a výnosnost různích typů lučních porostů. Rostl. Výr. 14, č 3: 233-241.

VINK, K. Y VAN STRAALEN, N., 1999. Effects of benomyl and diazinon on isopod-mediated leaf litter decomposition in microcosms. Pedobiología 43, 345-359.

VONLUTZOW, M. Y OTTOW, J. C. G., 1994. Effect of conventional and biological farming on microbial biomass and its nitrogen turnover in agriculturally used luvisoils of the Friedberg plains. Zeitschrift Pflanzenernahrung und Bodenkunde 157 (5), 359-367.
WILD, A. 1992. Condiciones del suelo y desarrollo de las plantas según Russell. Versión Española de P. Urbano Terrón y C. Rojo Fernández. Mundi-Prensa. Madrid. España, 1045 p. YOUNG, C. C., 1997. Polyamines in humic acid and their effect on radical growth of lettuce seedlings. Plant and Soil 195 (1), 143-149.

ZANCADA, M. C. Y SÁNCHEZ, A., 1994. Papel de los nemátodos en la biología del suelo. Boletín de la Real Sociedad Española de Historia Natural (Sección Biología) 91, 49-56.

ZENG, M., CAMPBELL, A. G. Y MAHLER, R. L., 1993. Log yard fines as a soil amendments pot \& fields studies. Communications in Soil Science and Plant Analysis 24 (1516): 2025-2041. 